\title{
SENSITIVITY OF TRANSCRIPTION BY PURIFIED STREPTOMYCES \\ ANTIBIOTICUS RNA POLYMERASE TO ACTINOMYCIN
}

\author{
Gearge H. Jones \\ Department of Cellular and Molecular Biology \\ Division of Biological Sciences \\ The University of Michigan \\ Ann Arbor, Michigan 48109
}

Received August 4,1978

\section{SUMMARY}

DNA-dependent RNA polymerase has been purified 400-fold from $48 \mathrm{hr}$ old, actinomycin producing cells of Streptomyces antibioticus. Sodium dodecyl sulfate polyacrylamide gel electrophoresis of the purified $\mathrm{S}$. antibioticus polymerase reveals the presence of bands corresponding to the $\overline{\beta,} \beta^{\prime}$, and $\alpha$ subunits of Escherichia coli polymerase, but no $\sigma$ subunit. The purified S. antibioticus polymerase is also associated with a protein component of T45,000 daltons and it is suggested that this protein is produced by $1 \mathrm{imi}$ ted proteolysis of either the $\beta$ or $\beta$ ' subunits. "In vitro" studies have shown that transcription catalyzed by either $\underline{S}$. antibioticus or $\underline{E}$. coli RNA polymerase is inhibited to about the same extent by actinomycin.

In previous reports from this laboratory, it was shown that RNA synthesis catalyzed by crude extracts of actinomycin producing $\underline{S}$. antibioticus cells was less sensitive to inhibition by actinomycin than was synthesis catalyzed by extracts of nonproducing $\underline{S}$. antibioticus cells or $\underline{E}$. coli cells $(1,2)$. It was further shown that a partially purified RNA polymerase preparation from actinomycin producing $\underline{\mathrm{S}}$. antibioticus cells was capable of catalyzing transcription in the presence of actinomycin concentrations which completely inhibited transcription by $\underline{E}$. coli RNA polymerase (2). Since the $\underline{S}$. antibioticus polymerase was not purified to homogeneity, the possibility remained that the ability of the enzyme to catalyze actinomycin resistant transcription resulted from its association with some accessory factors rather than from some intrinsic differences in the structure of the enzyme as compared with polymerases from other prokaryotes. To examine this possibility, RNA polymerase has been purified 400-fold from 48 hour old, actinomycin producing celis of $\underline{s}$ antibioticus. The 
purified enzyme has been compared with E. coli RNA polymerase in terms of subunit structure, and sensitivity to actinomycin.

\section{MATERIALS AND METHODS}

S. antibioticus cells were grown for $48 \mathrm{hr}$ as described previously (2). The RNA polymerase assay was performed as previously described (2), except that each of the four nucleoside triphosphates was present at $0.7 \mathrm{mM}$. One enzyme unit represents the incorporation of 1 nmole of [3H]-UMP into an acid insoluble form after $10 \mathrm{~min}$ of incubation at $30^{\circ}$.

The sedimentation coefficient of the purified $S$. antibioticus RNA polymerase was determined in the Beckman model $E$ analytical uTtracentrifuge using u1traviolet optics. Measurements were made using 1.0 A280 unit of purified RNA polymerase which corresponded to about $0.7 \mathrm{mg}$ protein. Centrifugation was at $56,000 \mathrm{rpm}$ and photographs were taken at 4 minute intervals after reaching speed. Photographic negatives were scanned with a Joyce-Loebl densitometer and the resulting tracings were utilized to calculate S. Sodium dodecyl sulfate (SDS) polyacrylamide gel electrophores is was performed according to Laemmli (3). Gels were stained with Coomassie Brilliant Blue.

The RNA polymerase purification procedure is similar to that described by Burgess and Jendrisak for E. coli RNA polymerase (4), and will be reported in detail in a subsequent publication. Briefly, the purification involved polyethyleneimine precipitation of the polymerase from crude cell extracts, ammonium sulfate extraction, DNA-cellulose chromatography and gel filtration.

\section{RESULTS AND DISCUSSION}

Purification of RNA polymerase - Results of a typical purification of $\underline{S}$. antibioticus RNA polymerase are summarized in Table I. The enzyme was generally purified about 400-fold relative to the crude extract, and the yield of enzyme activity varied between $85-700 \%$ of that assayed in the crude extract.

The purified enzyme was not contaminated with RNase or DNase activities, al though DNase was detected eluting after the polymerase peak from Biogel A $1.5 \mathrm{~m}$ columns.

Subunit structure and size of the S. antibioticus RNA polymerase - The subunit structure of the purified polymerase was analyzed by SDS-polyacrylamide gel electrophoresis. Fig. 1 shows the electrophoretic pattern for the step 5 enzyme. Some minor bands are visible in the gel of Fig. 1, but these were not always observed in other polymerase preparations. The major bands observable in the gel suggest that the $\underline{S}$. antibioticus RNA polymerase has a subunit structure similar to that reported for $\underline{E}$. coli except that the pattern for the $\underline{S}$. antibioticus polymerase lacks a band corresponding to the o factor of the $\underline{E}$. coli 


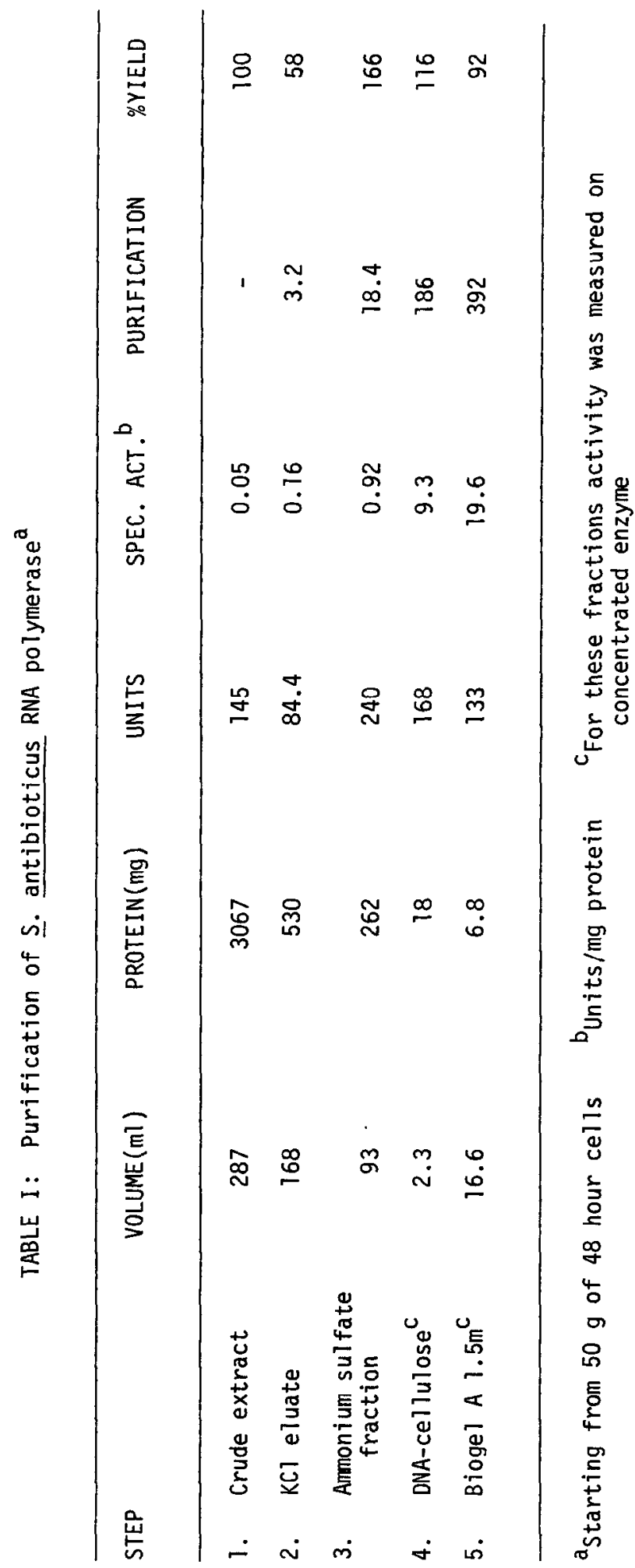




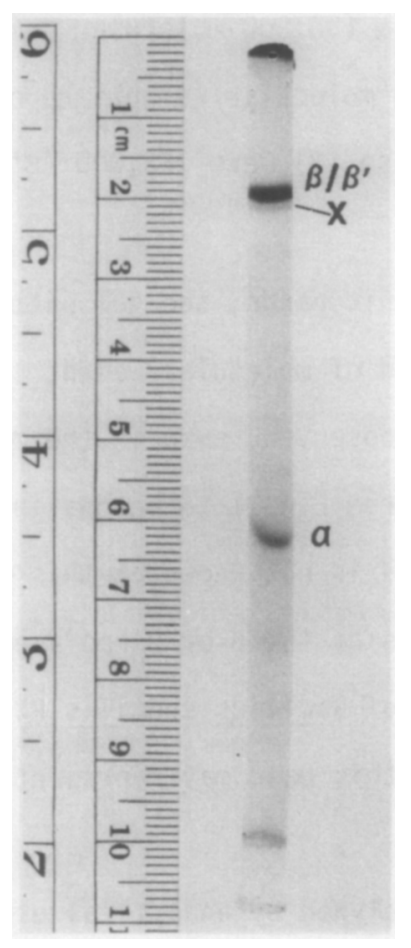

Fig. 1 - SDS-polyacrylamide gel electrophoresis of $12 \mu \mathrm{g}$ of purified $\underline{S}$. antibioticus RNA polymerase. The $\beta / \beta^{\prime}$ and $X$ bands can be clearly seen in this gel. Molecular weights of electrophoretic bands were determined using the following standards run on parallel gels: $\beta^{\prime}, \beta, \sigma$ and $\alpha$ subunits of $E$. coli RNA polymerase, bovine serum albumin, ovalbumin, DNase I, immunoglobuTin light chain and cytochrome $c$. The acrylamide monomer concentration was $8.7 \%$.

enzyme. In addition, the $\beta$ and $\beta^{\prime}$ bands were not resolved by SDS-polyacrylamide gel electrophoresis, even at acrylamide concentrations as low as $7 \%$. However, these two subunit bands could be resolved by electrophoresis in the presence of urea and SDS (manuscript in preparation). It should also be noted that the protease inhibitor, phenylmethylsulfonylfluoride, was included in all buffers used in the purification and storage of the polymerase. When this inhibitor was omitted from buffers, several bands in addition to those shown in Fig. 1 were observed upon electrophoresis of the purified enzyme. By analogy with E. coli polymerase, the largest subunits are referred to as $\beta$ and $\beta^{\prime}$ and have molecular weights of about 155,000 as determined by gel electrophoresis. Fig. 1 also shows that the $\underline{S}$. antibioticus polymerase possesses a subunit with 
mobility corresponding to the a $(50,000$ molecular weight) subunit of the $\underline{E}$. coli polymerase. The corresponding molecular weights reported by Burgess and Jendrisak for $\underline{E}$. coli polymerase $(3)$ were $165,000\left(\beta^{\prime}\right), 155,000(\beta), 87,000$ $(\sigma)$ and $39,000(\alpha)$.

In addition to these subunit bands, the gel pattern of step 5 enzyme also revealed the presence of a band of molecular weight 745,000 (Band $X$ of Fig. 1 )

This band was always observed, even in the most highly purified enzyme preparations and can be seen from Fig. 1 to be distinct from the $\beta^{\prime}$ and $\beta$ bands. The source of this protein band is not known at this time but it may have been produced by limited proteolysis of the $\beta$ or $\beta^{\prime}$ polymerase subunits. Limited proteolysis of the $\beta^{\prime}$ subunit of Bacillus subtilis RNA polymerase has been reported (5). Alternatively, this band may represent the $\sigma$ factor of the S. antibioticus polymerase.

When step 5 enzyme was analyzed by analytical ultracentrifugation in $0.5 \mathrm{M}$ $\mathrm{KCl}$, a sedimentation coefficient of 145 was obtained. This value is somewhat lower than that reported for E. Coli RNA polymerase (15S, reference 6). Actinomycin sensitivity of transcription by purified polymerases As reported previously (2), a partially purified $\underline{S}$. antibioticus RNA polymerase preparation catalyzed transcription at actinomycin concentrations which inhibited transcription by $\underline{E}$. coli RNA polymerase. The major goal of the studies presented in this report was to determine whether highly purified $\underline{S}$. antibioticus polymerase retained this property. In Fig. 2, the effects of actinomycin on transcription of calf thymus and $S$. antibioticus DNA's by $\underline{S}$. antibiocitus and E. coli polymerases are shown. In contrast to the results obtained with crude S. antibioticus extracts and partially purified RNA polymerase, there was little difference in the actinomycin sensitivity of transcription catalyzed by $\underline{S}$. antibioticus RNA polymerase as compared with the E. coli enzyme. With both purified enzymes, a given concentration of actinomycin inhibited transcription of $S$. antibioticus DNA to a somewhat greater extent than transcription of calf thymus DNA. These data suggest that the previous observation of actinomycin 


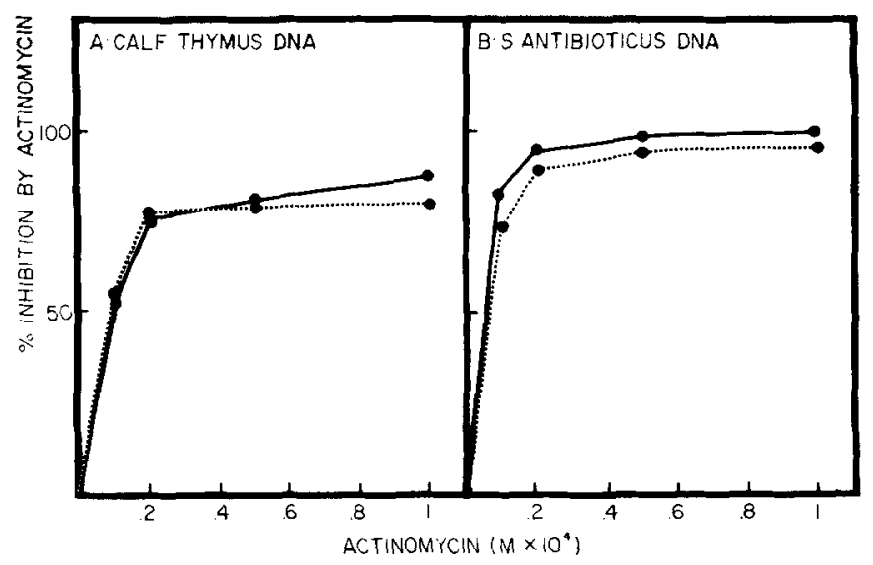

Fig. 2 - Effects of actinomycin on transcription of calf thymus and $S$. antibioticus DNA's by $E$. coli and $S$. antibioticus RNA and $4 \mu \mathrm{g}$ of RNA poTymerase. Reaction mixtures $(10 \overline{01})$ contained $0.15 \mathrm{mg}$ of DNA and $4 \mu \mathrm{g}$ of RNA polymerase. Results are expressed as percentage inhibition of 3H-UMP incorporation by actinomycin. The absolute levels of incorporation with calf thymus or S. antibioticus DNA's were similar with a given polymerase. Solid line, transcription by $\underline{E}$. coli RNA polymerase; dashed line, transcription by $\underline{S}$. antibioticus potymerase.

resistant transcription by crude extracts and by partially purified $\underline{S}$. antibioticus RNA polymerase was due to the association of accessory factors with the polymerase and not to an intrinsic property of the enzyme itself.

The data of Fig. 2 thus indicate that step 5 S. antibioticus RNA polymerase has lost the ability to catalyze actinomycin resistant transcription which was observed with crude cell extracts and partially purified enzyme (2). This finding suggests that some substances removed during the purification are responsible for this property. If this interpretation is correct, one would predict that the sensitivity of transcription to actinomycin inhibition would increase as more highly purified polymerase preparations are used. This is, in fact, what is observed. In a previous report, for example, it was shown that $5 \times 10^{-5} \mathrm{M}$ actinomycin inhibited RNA synthesis catalyzed by a crude extract of 48 hour S. antibioticus cells by $15 \%$ and synthesis catalyzed by 110-fold purified enzyme by

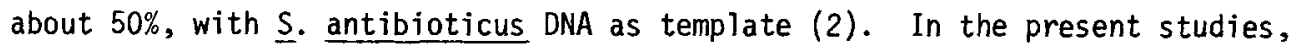
this actinomycin concentration inhibited $\left[{ }^{3} \mathrm{H}\right]$-UMP incorporation by $12 \%$ when crude extract was the polymerase source and $\underline{s}$. antibioticus DNA the template 
and by $43 \%$ when step 3 enzyme was the polymerase source (data not shown). As can be seen in Fig. 2, transcription of $\underline{S}$. antibioticus DNA by highly purified S. antibioticus RNA polymerase was inhibited by $94 \%$ at $5 \times 10^{-5}$ actinomycin. Thus, the ability to catalyze actinomycin resistant transcription does not seem to be an intrinsic property of the $\underline{S}$. antibioticus RNA polymerase.

\section{ACKNOWLEDGMENT}

This research was supported by grant number 5R01CA12752-06 from the National Cancer Institute, U. S. Public Health Service.

\section{REFERANCES}

1. Jones, G. H. (1975). Biophys. Biochem. Res. Commun. $\underline{63}, 469-475$.

2. Jones, G. H. (1976). Biochemistry 15, 3331-3341.

3. Laemmli, U. K. (1970). Nature (London) 227, 680-685.

4. Burgess, R. R. and Jendrisak, J. J. (1975). Biochemistry 14, 4634-4638.

5. Linn, T. G., Greenleaf, A. L., Shorenstein, R. G. and Losick, R. (1973). Proc. Natl. Acad. Sci. USA 70, 1865-1869.

6. Chamberlin, M. J., (1974). "The Enzymes" (P. D. Boyer, ed.) 3d edition, Vo1. 10, Academic Press, New York, N. Y., pp. 333-374. 